Subscriber access provided by King Abdullah University of Science and Technology Library

\title{
Letter
}

\section{The Role of Surface Tension in the Crystallization of Metal Halide Perovskites}

Ayan A. Zhumekenov, Victor M. Burlakov, Makhsud Saidaminov, Abdulilah Alofi, Md Azimul Haque, Bekir Turedi, Bambar Davaasuren, Ibrahim Dursun, Namchul Cho, Ahmed M. El-Zohry, Michele De Bastiani, Andrea Giugni, Bruno Torre, Enzo Di Fabrizio, Omar F. Mohammed, Alexander Rothenberger, Tom Wu, Alain Goriely, and Osman M. Bakr

ACS Energy Lett., Just Accepted Manuscript • DOI: 10.1021/acsenergylett.7b00468 • Publication Date (Web): 06 Jul 2017

Downloaded from http://pubs.acs.org on July 12, 2017

\section{Just Accepted}

"Just Accepted" manuscripts have been peer-reviewed and accepted for publication. They are posted online prior to technical editing, formatting for publication and author proofing. The American Chemical Society provides "Just Accepted" as a free service to the research community to expedite the dissemination of scientific material as soon as possible after acceptance. "Just Accepted" manuscripts appear in full in PDF format accompanied by an HTML abstract. "Just Accepted" manuscripts have been fully peer reviewed, but should not be considered the official version of record. They are accessible to all readers and citable by the Digital Object Identifier (DOI®). "Just Accepted" is an optional service offered to authors. Therefore, the "Just Accepted" Web site may not include all articles that will be published in the journal. After a manuscript is technically edited and formatted, it will be removed from the "Just Accepted" Web site and published as an ASAP article. Note that technical editing may introduce minor changes to the manuscript text and/or graphics which could affect content, and all legal disclaimers and ethical guidelines that apply to the journal pertain. ACS cannot be held responsible for errors or consequences arising from the use of information contained in these "Just Accepted" manuscripts. 


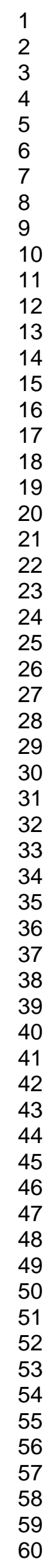

SCHOLARONE ${ }^{m}$

Manuscripts

7

25

26

27

29

30

32

33

34

35

36

37

39

40

41

42

44

45

46

47

48

50

51

53

54

55

57

58

59

60 


\title{
The Role of Surface Tension in the Crystallization of
}

\section{Metal Halide Perovskites}

\author{
Ayan A. Zhumekenov, ${ }^{\dagger, \perp}$ Victor M. Burlakov, ${ }^{\S,}{ }^{\text {Makhsud I. Saidaminov, },{ }^{\dagger}, \Delta}$ Abdulilah Alofi, ${ }^{\dagger}$ Md \\ Azimul Haque,,${ }^{\ddagger}$ Bekir Turedi, ${ }^{\dagger}$ Bambar Davaasuren, ${ }^{\ddagger}$ Ibrahim Dursun,${ }^{\dagger}$ Namchul Cho, ${ }^{\dagger, \#}$ Ahmed \\ M. El-Zohry, ${ }^{\dagger}$ Michele De Bastiani,${ }^{\dagger}$ Andrea Giugni,${ }^{\star}$ Bruno Torre, ${ }^{\star}$ Enzo Di Fabrizio,${ }^{\dagger}$ Omar F. \\ Mohammed,$^{\dagger}$ Alexander Rothenberger ${ }^{\star}$ Tom Wu, Alain Goriely, ${ }^{\S}$ Osman M. Bakr, ${ }^{\dagger}$, \\ † King Abdullah University of Science and Technology (KAUST), KAUST Solar Center, \\ Physical Sciences and Engineering Division (PSE), Thuwal 23955-6900, Saudi Arabia \\ $\$$ King Abdullah University of Science and Technology (KAUST), Physical Sciences and \\ Engineering Division (PSE), Thuwal 23955-6900, Saudi Arabia \\ $\S^{\S}$ Mathematical Institute, University of Oxford, Woodstock Road, Oxford OX2 6GG, UK
}

Corresponding Author

*E-mail: osman.bakr@kaust.edu.sa 
ABSTRACT. The exciting intrinsic properties discovered in single crystals of metal halide perovskites still await their translation into optoelectronic devices. The poor understanding and control of the crystallization process of these materials are current bottlenecks retarding the shift towards single crystal-based optoelectronics. Here we theoretically and experimentally elucidate the role of surface tension in the rapid synthesis of perovskite single crystals by inverse temperature crystallization (ITC). Understanding the nucleation and growth mechanisms enabled us to exploit surface tension to direct the growth of monocrystalline films of perovskites $\left(\mathrm{AMX}_{3}\right.$, where $\mathrm{A}=\mathrm{CH}_{3} \mathrm{NH}_{3}{ }^{+}$or $\mathrm{MA} ; \mathrm{M}=\mathrm{Pb}^{2+}, \mathrm{Sn}^{2+} ; \mathrm{X}=\mathrm{Br}^{-}, \mathrm{I}^{-}$) on the solution surface. We achieve up to $1 \mathrm{~cm}^{2}$-sized monocrystalline films with thickness on the order of the charge carrier diffusion length $(\sim 5-10 \mu \mathrm{m})$. Our work paves the way to control the crystallization process of perovskites, including thin film deposition, which is essential to advance the performance benchmarks of perovskite optoelectronics.

\section{TOC GRAPHICS}

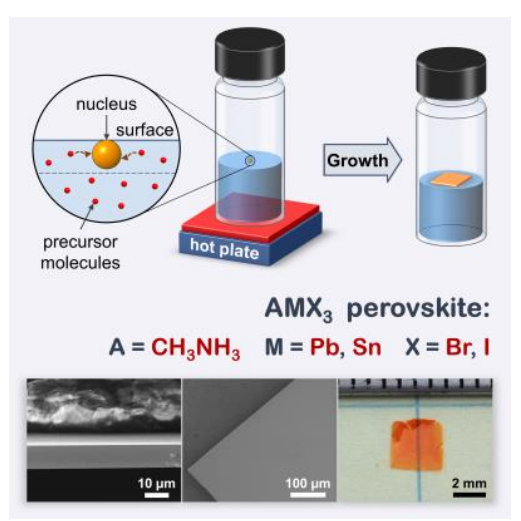


The performance of solid-state optoelectronic devices is usually dictated by the crystallinity of semiconductor materials used in the fabrication. Highly crystalline and monocrystalline semiconductors are the foundation of the most efficient solar cells, transistors, and light-emitting devices. ${ }^{1}$ Recently, metal halide perovskites with their intrinsically remarkable semiconducting properties have attained phenomenal success in optoelectronics. ${ }^{2-11}$ Yet despite these achievements, the majority of current perovskite-based devices still rely on polycrystalline thin films, which exhibit orders of magnitude inferior charge transport characteristics ${ }^{12-15}$ and an increased tendency to chemical degradation ${ }^{16-18}$ relative to their monocrystalline analogues. A desired shift towards single crystal-based devices is hindered by the necessity of synthesizing perovskite single crystals with geometries suitable for device applications. Though a number of solution-processed crystallization methods have been reported to date, ${ }^{12-14,19-28}$ none of them successfully achieved both large-area $\left(>1 \mathrm{~cm}^{2}\right)$ and high-aspect-ratio $\left(>10^{3}\right)$ perovskite monocrystalline films (PMFs). The inability to direct the crystallization process stems from a poor understanding of its mechanism.

Here, to bridge this technological gap, we thoroughly investigate the mechanistic origins of crystallization of metal halide perovskites, particularly focusing on their rapid synthesis by inverse temperature crystallization (ITC) ${ }^{14,19-21,29}$. We show that surface tension plays a central role in nucleation and growth of a crystal phase. We propose a mechanism, according to which the ITC starts with a nucleation at the solution surface layer due to the effect of surface tension. The growth of the nucleus into a crystal continues on the solution surface until it reaches the size when surface tension can no longer keep the crystal afloat. Taking advantage of this discovery, we design a general strategy for growing large-area monocrystalline films with high aspect ratios $\left(\sim 10^{3}\right)$, referred to here as surface tension-controlled inverse temperature crystallization (ST- 
ITC). The understanding of ITC mechanism and the development of ST-ITC for monocrystalline film growth creates a pathway to achieving optoelectronic devices based on perovskite single crystals.

ITC is a method for rapid synthesis of sizable perovskite single crystals based on their solubility loss upon heating in certain organic solvents. ${ }^{14,19-21,29} \mathrm{~A}$ recent report suggested a potential mechanism for ITC, in which the main driving force was proposed to be the supersaturation of ions as a result of the acid-induced dissolution of colloids. ${ }^{30}$ Although this mechanism may be relevant to the rapid crystallization of MA-based perovskites, the recent discovery of inverse solubility of cesium-based perovskites in DMSO (an aprotic solvent, which does not have an acid decomposition product $)^{31-34}$ requires an alternative mechanism for ITC. To this end, we present below a generalized theory applicable to a broad range of metal halide perovskites.

Nucleation analysis. The crystallization is a two-step process, which includes nucleation and growth of a solid phase. The basic physics of nucleation is illustrated using classical nucleation theory, ${ }^{35-38}$ according to which the nucleation rate $R_{N}$ exponentially decreases with the nucleation barrier $\Delta$ :

$$
R_{N} \propto \exp \left[-\frac{\Delta}{T}\right]
$$

where $T$ is temperature.

We propose that nucleation in ITC is driven by dissociation of precursor-solvent complexes at elevated temperatures. ${ }^{14}$ Complex dissociation generates supersaturation of the isolated precursor molecules, which then nucleate into particles by overcoming the nucleation barrier $\Delta$. For illustration purposes, consider a single-component precursor $\mathrm{A}$ in the solution, which forms 
nuclei composed of pure A-molecules and complexes with the solvent $\mathrm{S}$ that is $\mathrm{AS}_{j}$. The concentration of the complexes is determined by the complex binding energy $E_{C}=\varepsilon_{C}-\varepsilon_{A}-j \varepsilon_{S}$ measured relative to the energies of A-molecules $\left(\varepsilon_{A}>0\right)$ and solvent molecules $\left(\varepsilon_{S}>0\right)$. At the solution surface these energies are lower, i.e. $\varepsilon_{A S}<\varepsilon_{A}$ and $\varepsilon_{S S}<\varepsilon_{S}$, since the surface molecules are in strain due to surface tension (Figure 1A).
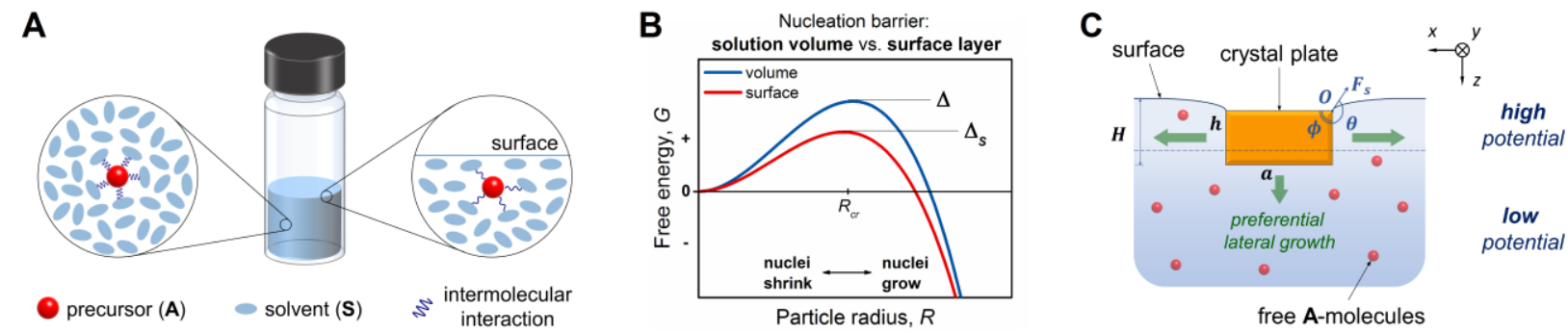

Figure 1. (A) Schematic of change in molecular interaction energies in the volume (left) and the surface layer (right) of the solution. Due to surface tension effect, the intermolecular distances in the surface layer are increased hence decreasing corresponding interaction energy. (B) Graph illustrating the lower nucleation barrier for the solution surface layer compared to that in the solution volume. (C) Schematic of crystal growth during ITC. The free precursor molecules in the surface layer (above the dashed line) mainly attach to the sides of the nucleus (due to a higher free energy gain) resulting in a lateral growth of the crystal plate. The crystal plate is kept afloat by the solution surface tension.

The nucleation barrier can be expressed as the difference in free energy of molecules in the nucleated particle relative to their energy in the solution:

$$
\Delta=\frac{4}{3} \pi R_{c r}{ }^{3} \cdot\left(-\varepsilon+\varepsilon_{A}-k_{B} T \cdot \ln N_{A}\right)+4 \pi \gamma R_{c r}{ }^{2}=\frac{16 \pi}{3} \cdot \frac{\gamma^{3}}{\left(\varepsilon-\varepsilon_{A}+k_{B} T \cdot \ln \left(N_{\mathrm{A}}\right)\right)^{2}}
$$

where $R_{c r}$ is the critical nucleus radius, $\gamma$ is the particle's surface energy, $\varepsilon$ is the cohesive energy of A-molecules in the particle, $N_{A}$ is the mole fraction of isolated A-molecules. As the surface 
layer is very thin, just a few intermolecular distances, the concentration of individual Amolecules in it should be very close to that in the volume. Therefore, eq 2 shows that the nucleation barrier decreases with decreasing the molecular binding energy $\varepsilon_{A}$. For A-molecules in the surface layer this decrease is due to surface tension such that $\varepsilon_{A S}=\varepsilon_{A}-\varepsilon_{\text {surf }}$, where $\varepsilon_{\text {surf }}>0$ is the surface tension-related elastic energy per A-molecule in the surface layer. Then the nucleation barrier takes the form:

$$
\Delta_{S}=\frac{16 \pi}{3} \cdot \frac{\gamma^{3}}{\left(\varepsilon+\varepsilon_{\text {surf }}-\varepsilon_{A}+k_{B} T \cdot \ln \left(N_{\mathrm{A}}\right)\right)^{2}}
$$

This equation shows that the nucleation barrier at the surface layer is lower, hence the nucleation rate is higher than that in the solution volume (Figure 1B). We have also to emphasize that the higher is surface tension and accordingly $\varepsilon_{\text {surf }}$, the lower is nucleation barrier at the solution surface, hence surface nucleation is easier.

Growth analysis. The crystal growth rate can be treated within the Transition State Theory, ${ }^{39,40}$ according to which the reaction rate is higher if the molecule in the initial state (solution) has higher chemical potential. The latter is true for A-molecules in the surface layer, which solvation energy $\left(-\varepsilon_{A S}\right)$ is increased due to surface tension (Figure S1A). As a result, the edge sides of a crystal suspended on the solution surface are expected to grow faster than the bottom side, resulting in aspect ratios $>1$ (Figure 1C).

Floatation analysis. The floatation of heavy solid objects on liquid surfaces arises from the interplay of several factors but is primarily due to the surface tension of a liquid. For illustrating the effect, consider a crystal plate of $a \times a \times h$ dimensions held on the solution surface (Figure 
1C). Such a crystal plate of density $\rho$ forms at its edges an effective contact angle $\theta>90^{\circ}$ with the liquid. ${ }^{41-43}$ The resultant equation taking into account the net force balance is as follows:

$$
a h \approx \frac{4 \sigma_{\text {sol }} \sin \left(\theta-90^{\circ}\right)}{\left(\rho-\rho_{\text {sol }}\right) g}
$$

where $\rho_{\text {sol }}$ and $\sigma_{\text {sol }}$ are the solution density and surface tension coefficient, respectively, $g$ is the gravitational constant $\left(9.81 \mathrm{~m} / \mathrm{s}^{2}\right)$. As is clear from this equation, solutions with high density and surface tension coefficient along with less tendency to wet the crystal plate are more likely to keep large crystals afloat on their surfaces. Thus, the use of highly concentrated solutions can prolong the crystal growth on the solution surface to a greater extent, as they provide both high $\rho_{\text {sol }}$ and $\sigma_{\text {sol }}$ values (Table S2) and also poorly wet the crystal surface (Figure S1B-S1C).
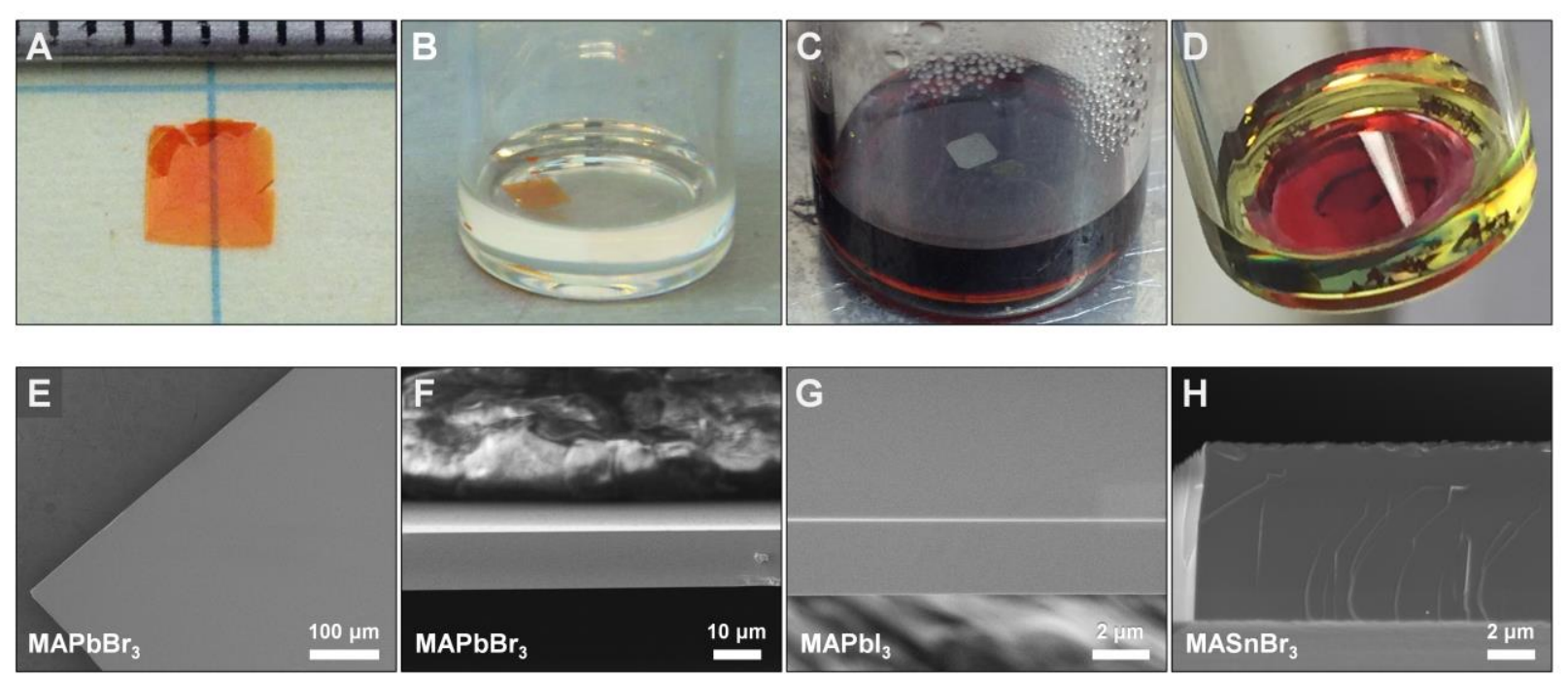

Figure 2. Photographic images of (A) free-standing $\mathrm{MAPbBr}_{3} \mathrm{PMF}$, and (B) $\mathrm{MAPbBr}_{3}$, (C)

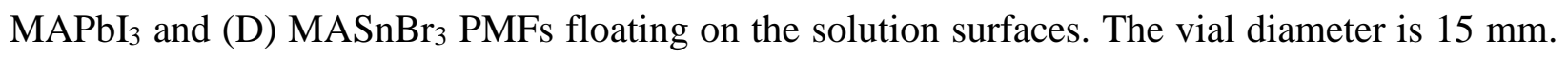
(E) Top-view SEM image of $\mathrm{MAPbBr}_{3}$ PMF. Side-view SEM images of (F) $\mathrm{MAPbBr}_{3},(\mathrm{G})$ $\mathrm{MAPbI}_{3}$ and $(\mathrm{H}) \mathrm{MASnBr}_{3} \mathrm{PMFs}$. 
Based on our theoretical analysis, we hypothesized that crystallization process could be controlled in a way that enables the growth of large-area PMFs on the solution surface. To validate our hypothesis, we developed surface tension-controlled inverse temperature crystallization (ST-ITC) method, which uses solvent systems providing both the inverse solubility behavior and the high surface tension coefficient $\left(\sigma_{s o l}\right)$ for a perovskite solution.

We started by choosing a suitable solvent system for the growth of $\mathrm{MAPbBr}_{3} \mathrm{PMFs}$. The highest achievable concentration of $\mathrm{MAPbBr}_{3}$ in $\mathrm{DMF}$ is $1.5 \mathrm{M}$ at room temperature. ${ }^{29}$ However, only bulk crystals are produced from this solution upon its heating. Therefore, in order to arrive at PMFs only, a solvent with inherent high surface tension coefficient such as DMSO $\left(\sigma_{D M S O}=42.8\right.$ $\mathrm{mN} / \mathrm{m}$ vs $\left.\sigma_{D M F}=35.2 \mathrm{mN} / \mathrm{m}\right)^{44}$ is needed. In addition, DMSO better dissolves $\mathrm{MAPbBr}_{3}$ than DMF, which is essential to further increase $\sigma_{\text {sol }}$. (Indeed, $\sigma_{\text {sol }}$ increases with the concentration of perovskite solution as will be shown further). Though $\mathrm{MAPbBr}_{3}$ does not display ITC in pure DMSO, fortunately, we discovered that it does in the mixture of DMF and DMSO. DMF most likely provides inverse solubility, while DMSO increases the solubility of precursors and guarantees high $\sigma_{\text {sol }}$.

To understand the effect of composition on ST-ITC, we mixed the solutions A (1.5 M $\mathrm{MABr} / \mathrm{PbBr}_{2}$ in $\left.\mathrm{DMF}\right)$ and $\mathrm{B}\left(4.2 \mathrm{M} \mathrm{MABr} / \mathrm{PbBr}_{2}\right.$ in $\left.\mathrm{DMSO}\right)$ in various ratios. We observed that upon heating to $90-100{ }^{\circ} \mathrm{C}$, A-B mixtures with $80-90 \%$ of $\mathrm{B}$ (by volume) produced $\mathrm{MAPbBr}_{3}$ PMFs only (Figure 2B). Whereas the further decrease of the B content $(\leq 70 \%)$ resulted mainly in bulk crystals (Figure S2A). Hence, we can conclude that there is a threshold surface tension value above which only PMFs grow. We will discuss this in more details in discussions sections. 
We next use our knowledge to grow $\mathrm{MAPbI}_{3} \mathrm{PMFs}$. By analogy, here we used GBL as a solvent providing inverse solubility, and DMSO as a solvent providing high $\sigma_{\text {sol }}$. We found that typical dodecahedral-MAPbI 3 cannot be grown in the PMF-form using ST-ITC method, whereas recently reported cuboid-MAPbI 3 can (Figure S2). ${ }^{45}$ To arrive at the cuboid shape, we used 2:1 molar ratio of $\mathrm{MAI} \mathrm{PbI}_{2}$. We separately prepared concentrated solutions of $2 \mathrm{MAI} / \mathrm{PbI}_{2}$ in $\mathrm{GBL}$ (2.5 M, solution C) and DMSO (4.5 M, solution $\mathrm{D})$, and then mixed them in 1:1 ratio by volume. Thin square black plates with truncated corners appeared on the solution surface upon heating the mixture to $100-110^{\circ} \mathrm{C}$ (Figure $2 \mathrm{C}$ ). The films have a specular top-surface.

Finally, we also generalized ST-ITC to tin halide perovskites. We found that $\mathrm{MASnBr}_{3}$ is well dissolved in DMF at room temperature and displays inverse solubility in the solvent. Hence, we were able to achieve sufficiently high $\sigma_{\text {sol }}$ without involving a second solvent. Heating $5 \mathrm{M}$ solution of $\mathrm{MABr} / \mathrm{SnBr}_{2}$ in $\mathrm{DMF}$ to $60-70{ }^{\circ} \mathrm{C}$ resulted in thin square red plates (Figure $2 \mathrm{D}$ ). To the best of our knowledge, this is the first demonstration of inverse solubility behavior in tin halide perovskites.

Top-view scanning electron microscopy (SEM) image of $\mathrm{MAPbBr}_{3}$ PMF shows a smooth surface comparable with that of bulk crystals (Figure 2E). From side-view SEM images (Figure $2 \mathrm{~F}-2 \mathrm{H}$ ), we estimated the film thicknesses to vary from 5 to $20 \mu \mathrm{m}$, reaching down to $10 \mu \mathrm{m}$ for $\mathrm{MAPbBr}_{3}$ and $\mathrm{MASnBr}_{3} \mathrm{PMFs}$, and $5 \mu \mathrm{m}$ for $\mathrm{MAPbI}_{3} \mathrm{PMFs}$. We note that the thickness of $\mathrm{MAPbI}_{3} \mathrm{PMFs}$ is in the same range with the charge carrier diffusion length, ${ }^{14}$ suggesting its potential use for optoelectronic devices. The typical aspect ratio of grown PMFs is about $10^{3}$ in line with our theoretical analysis. 
A

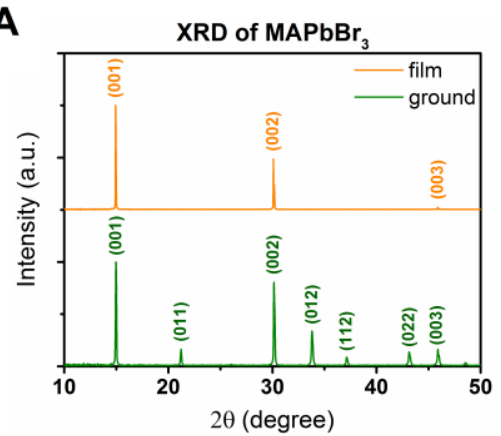

D Absorption and PL spectra of $\mathrm{MAPbBr}_{3}$

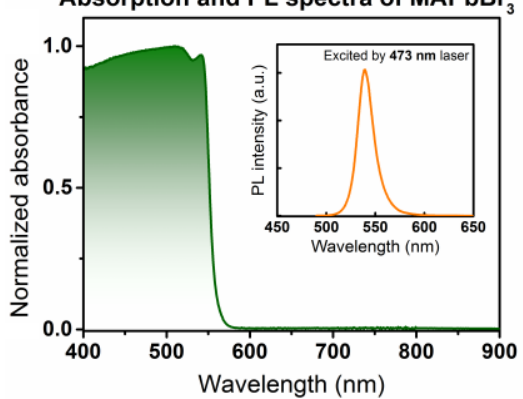

B

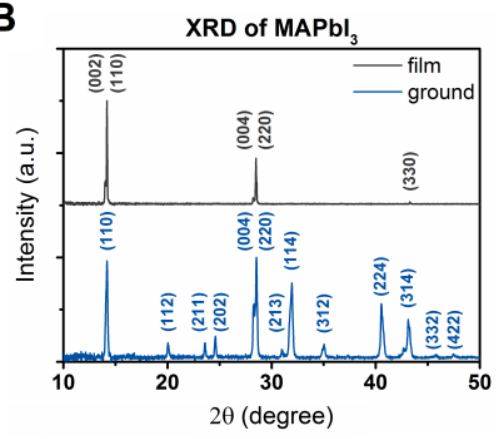

E

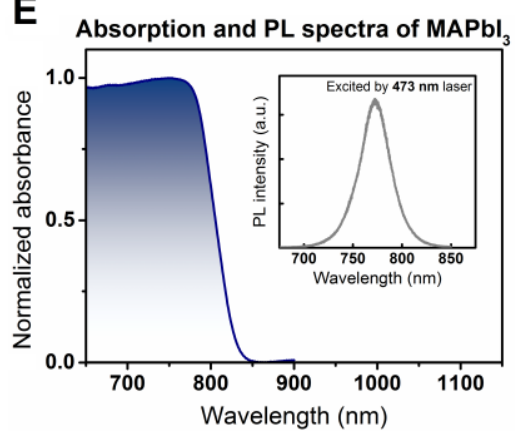

C

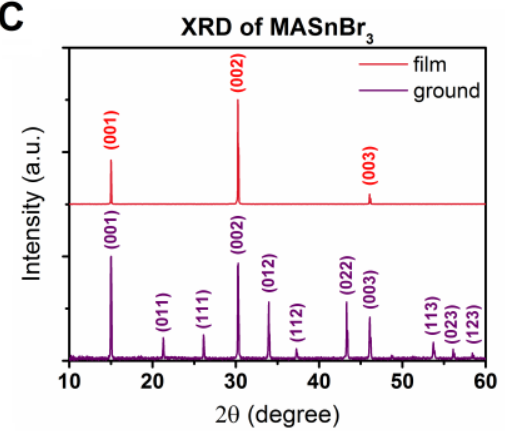

$\mathbf{F}$

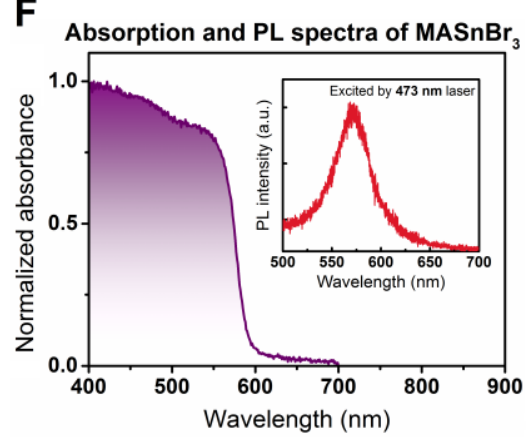

Figure 3. XRD patterns of free-standing and ground (A) $\mathrm{MAPbBr}_{3}$, (B) $\mathrm{MAPbI}_{3}$ and (C) MASnBr 3 PMFs. Absorption and PL spectra of (D) $\mathrm{MAPbBr}_{3}$, (E) $\mathrm{MAPbI}_{3}$ and (F) $\mathrm{MASnBr}_{3}$ PMFs.

Next, we characterized PMFs by X-ray diffraction (XRD). Powder XRD patterns of ground crystals confirmed the presence of single cubic phase of $\mathrm{MAPbBr}_{3}$ and $\mathrm{MASnBr}_{3}$ perovskites, and single tetragonal phase of $\mathrm{MAPbI}_{3}$ perovskite (Figure $3 \mathrm{~A}-3 \mathrm{C}$ ). ${ }^{14,46}$ For $\mathrm{MASnBr} 3$, the calculated unit cell parameter $\left(a=5.89 \AA\right.$ ) was found to be consistent with previous reports. ${ }^{46}$

The XRD patterns of free-standing PMFs have reflections only from particular families of planes (Figure 3A-3C), indicating that their lateral growth on the solution surface proceeds along certain crystallographic directions. For example, as seen from Figure 3A-3B, both $\mathrm{MAPbBr}_{3}$ and $\mathrm{MASnBr}_{3} \mathrm{PMFs}$ show only those diffraction peaks which correspond to $(00 l)$ family of planes, suggesting the top facet of these films to be (001)-oriented. For $\mathrm{MAPbI}_{3}$, we observed two strong adjacent peaks at $2 \theta=14.01^{\circ}$ and $14.17^{\circ}$ corresponding to (002) and (110) planes, respectively, 
and another two adjacent peaks at $2 \theta=28.21^{\circ}$ and $28.49^{\circ}$ corresponding to (004) and (220) planes, respectively. We suppose that such $(002) /(110)$-orientation of the $\mathrm{MAPbI}_{3} \mathrm{PMFs}$ is related to the choice of molar ratio of precursors. Namely, increasing the $\mathrm{MAI} / \mathrm{PbI}_{2}$ ratio from $1: 1$ to $2: 1$ shifts the equilibrium towards the formation of iodine-rich lead-complexes, ${ }^{47-49}$ which preferentially integrate to (200) facet (Figure S3). The resultant shape is, thus, determined by slower growing (002) and/or (110) planes, which are observed here.

Further, we performed single crystal XRD analysis on $\mathrm{MAPbBr}_{3} \mathrm{PMF}$. The results revealed the absence of other domains and confirmed the monocrystalline nature of the films grown by STITC method (Figure S4). The PMF crystallinity was also assessed by high-resolution XRD. The rocking curve of the (001) diffraction plane of $\mathrm{MAPbBr}_{3}$ PMF shows a narrow peak with a fullwidth at half-maximum (FWHM) of $0.042^{\circ}$ (Figure S5) on par with high quality perovskite single crystals and monocrystalline films. ${ }^{15,27}$ The trap state density of $5.3 \times 10^{11} \mathrm{~cm}^{-3}$ estimated by space-charge-limited current (SCLC) technique was found to be of the same order as for previously reported $\mathrm{MAPbBr}_{3} \mathrm{PMFs}^{27}$ but slightly higher than for bulk single crystals ${ }^{13,14}$ possibly due to surface traps induced by larger contact area of PMFs with the solution (Figure S6 and Table S1).

The Raman study of the near-top-surface layer of $\mathrm{MAPbBr}_{3} \mathrm{PMF}$ showed the absence of precursor residues and homogenous chemical/structural composition throughout the investigated volume $\left(70 \times 50 \times 1 \mathrm{~m}^{3}\right)$, indicating no degradation and restructuring of PMF takes place upon exposure to air and the solvent vapor during its growth on the solution surface (Figures S13-S15, see Supporting Information for more details). 
We also investigated the optical properties of the grown PMFs using steady-state absorption and photoluminescence (PL) spectroscopies (Figure 3D-3F). The absorption profiles of PMFs have a sharp band edge cut-off at $542 \mathrm{~nm}$ for $\mathrm{MAPbBr}_{3}$ and $770 \mathrm{~nm}$ for $\mathrm{MAPbI}_{3}$ in line with bulk single crystals. ${ }^{13,14,50}$ In case of $\mathrm{MASnBr}_{3}$, the band edge was estimated to be $552 \mathrm{~nm}$. However, noteworthy that $\mathrm{Sn}^{2+}$ is likely to partially oxidize in air to $\mathrm{Sn}^{4+}$, resulting in a long tail in the absorption spectrum. PL peak positions for $\mathrm{MAPbBr}_{3}$ and $\mathrm{MAPbI}_{3}$ were found to center at 539 and $773 \mathrm{~nm}$, respectively, slightly blue-shifted compared to bulk crystals ${ }^{13,14}$ consistent with recent reports ${ }^{51}$. Although the solution-processed tin halide perovskites were previously reported to be PL-inactive, ${ }^{52}$ for $\mathrm{MASnBr}_{3}$ PMFs we still observed a peak at $572 \mathrm{~nm}$ with a very weak intensity.

As a proof of concept, we fabricated a self-powered Schottky photodetector employing $\mathrm{MAPbBr}_{3} \mathrm{PMF}$ sandwiched between $\mathrm{Pt}$ and $\mathrm{Au}$ electrodes (Figure S16). The current $\mathrm{ON}-\mathrm{OFF}$ ratio of about $10^{4}$ was observed at zero bias. Owing to small transverse dimension of the PMF, the responsivity $(87 \mathrm{~mA} / \mathrm{W}$ at $0 \mathrm{~V}$ ) of the photodetector was found to be 40 times higher than that of the previously reported one based on $\mathrm{MAPbBr}_{3}$ single crystal with $150 \mu \mathrm{m}$ thickness. ${ }^{53}$ Furthermore, an excellent detectivity of $10^{12}$ Jones at zero bias and fast response speed $\left(t_{\text {rise }}=32\right.$ $\mu \mathrm{S} ; t_{\text {decay }}=60 \mu \mathrm{S}$ ) were achieved. Notably that the device characteristics are comparable to the state-of-the-art perovskite photodetectors based on single crystals, ${ }^{5,32,54-58}$ underpinning the high quality of the PMFs (Table S6). 

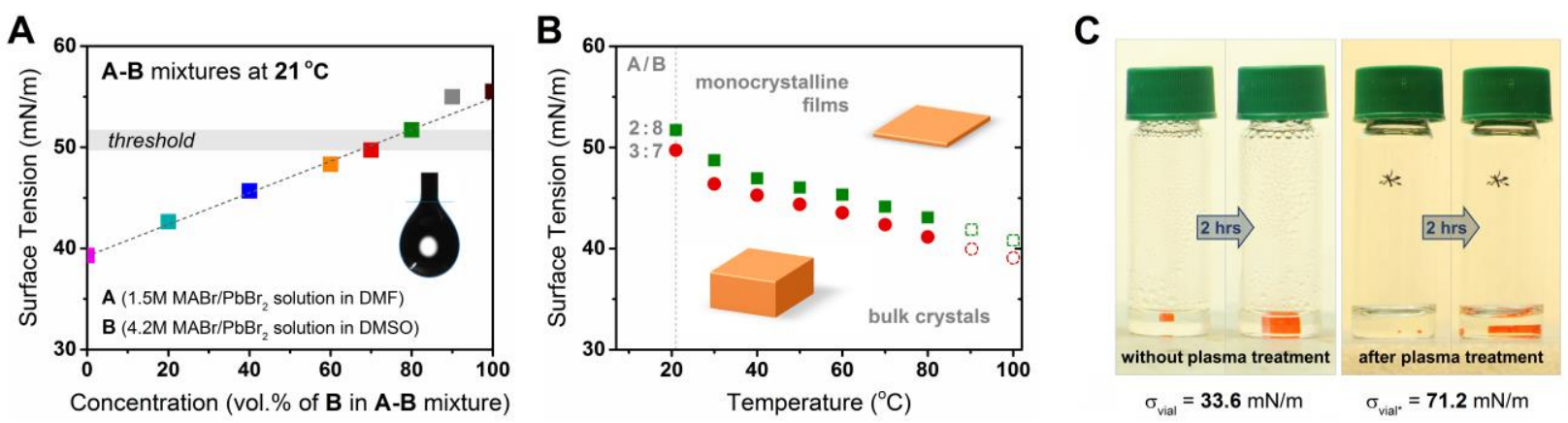

Figure 4. Dependence of surface tension coefficient on: (A) concentration expressed here as the solution B content in A-B mixture, (B) temperature for A-B mixtures with $70 \%$ and $80 \%$ of B, resulting in bulk crystals and PMFs, respectively. (C) Demonstration of altering the nucleation site from solution-air to solution-vial interface by treating vials with air plasma.

Unlike standard ITC, ST-ITC involves highly concentrated solutions. Particularly, as demonstrated for $\mathrm{MAPbBr}_{3}$, only PMFs (without bulk crystals) grow from more concentrated AB mixtures with the B content of $80 \%$ and above (Figure 4A). These B-rich compositions possess lower density than the crystalline phase $\left(\rho=3.582 \mathrm{~g} / \mathrm{cm}^{3}\right)$ (Table S2). Therefore, the floatation of crystals is supported primarily by the solution surface tension. Next, we investigated the bottom threshold value $\left(\sigma^{t r s}\right)$ for the solution surface tension, which maintains the growth of PMFs only. Using the pendant drop method we measured $\sigma_{\text {sol }}$ for a range of A-B mixtures and found $\sigma^{t r s}$ to be $50.7 \pm 1.0 \mathrm{mN} / \mathrm{m}$ for room temperature mixtures (Figure $4 \mathrm{~A}$ ), or $39.9 \pm 0.9 \mathrm{mN} / \mathrm{m}$ for mixtures at the crystallization point $\left(100{ }^{\circ} \mathrm{C}\right.$ ) (Figure $4 \mathrm{~B}$, see Supporting Information for more details). Based on eq 4, we note that over $1 \mathrm{~cm}^{2}$-area PMF can be held on the solution surface by this high surface tension value.

Obviously, the observation of PMF growth is a direct evidence of surface nucleation. Nevertheless, it is worth mentioning that for less concentrated solutions the surface nucleation is still possible, but less pronounced and results in bulk crystals. As seen from Supporting Movie, for solution A in 3 out of 8 vials the crystals appear at the solution surface, but then sinks when 
reaches a critical size. In the rest cases, the crystals appear on the bottom at the solution-vial interface. Such tendency conforms with our theoretical analysis, as the increased $\sigma_{s o l}$ leads to preferential nucleation at the surface layer.

While solution-air interface plays a critical role in nucleation as we discussed above, solutionvial interface might also introduce nucleation. We performed ITC from solution A in vials without and after air plasma treatment (Figure $4 \mathrm{C})$. The surface energy of vials $\left(\sigma_{\text {vial }}\right)$ estimated by the Owens-Wendt-Rabel-Kaelble (OWRK) method me-61 $^{59}$ found to increase from 33.6 $\mathrm{mN} / \mathrm{m}$ to $71.2 \mathrm{mN} / \mathrm{m}$ after the treatment (Figure $\mathrm{S} 11$ ). Though the nucleation in untreated vials was observed at both sites almost equally, the plasma-treated vials with high surface energy stimulated nucleation preferentially at the solution-vial interface (Figure 4C). Based on the Young's equation $^{62}$ (eq S17), we speculate that higher surface energy of vial gives a rise to the solution-vial interface energy $\sigma_{\text {sol-vial }}$ (Table S5), thus making it more favorable nucleation site. This effect of surface energy could potentially be utilized for the large-area on-substrate growth of PMFs.

In summary, we uncovered the role of surface tension in the rapid synthesis of metal halide perovskites by inverse temperature crystallization (ITC) and supported it by experimental studies. Equipped by this new knowledge we designed a method termed surface tensioncontrolled inverse temperature crystallization (ST-ITC) to achieve large-area (up to $1 \mathrm{~cm}^{2}$ ) perovskite monocrystalline films with thickness on the order of charge carrier diffusion length $(\sim 5-10 \mu \mathrm{m})$ suitable for device applications. The versatility of ST-ITC enabled the synthesis of not only lead halide perovskites $\left(\mathrm{MAPbBr}_{3}\right.$ and $\left.\mathrm{MAPbI}_{3}\right)$ but also tin halide perovskites $\left(\mathrm{MASnBr}_{3}\right)$, thus enriching the ITC library with tin-based perovskites. 
Even though we demonstrated the role of surface tension in crystallization of perovskites from solution only, we note that it plays a critical role in thin film deposition as well. Recently, while this work was under preparation, Grätzel and co-workers demonstrated that illumination can alter the surface tension between phases, which in turn affects the thin film morphology, grain sizes and the device performance. ${ }^{63}$ The detailed study of the effect of surface tension on the ITC phenomenon is, thus, not only intriguing from a fundamental viewpoint, but is expected to impact future progress towards eliminating the grain boundaries and improving the crystallinity of perovskite thin films for fully single crystal-based stable devices.

\section{ASSOCIATED CONTENT}

\section{Supporting Information.}

Materials and Methods. Details of all experimental procedures. Extended theoretical analysis including derivations. The details of ST-ITC. Crystallinity analysis. Trap state density analysis. The PL spectra correction. Extended results of pendant drop and contact angle measurements. Details of the OWRK method. The Raman study of MAPbBr 3 PMF. Characteristics of the selfpowered Schtottky photodetector based on $\mathrm{MAPbBr}_{3} \mathrm{PMF}$. Comparison of the state-of-the-art perovskite photodetectors based on single crystals. (PDF) Supporting Movie. The growth of $\mathrm{MAPbBr}_{3}$ single crystals from 1.5 M solution in DMF in vials without and after air plasma treatment. (AVI)

\section{AUTHOR INFORMATION}

\section{Author Contribution}


$\perp$ A.A.Z. and V.M.B. contributed equally to this work.

\section{Present Addresses}

${ }^{\Delta}$ M.I.S.: Department of Electrical and Computer Engineering, University of Toronto, Toronto, Ontario M5S 3G4, Canada.

\# N.C.: Department of Energy System, Soonchunhyang University, Asan, South Korea, 31538.

\section{Notes}

The authors declare no competing financial interests.

\section{ACKNOWLEDGMENT}

The authors thank Dr. Murali Banavoth for assistance with Scanning Electron Microscopy, Dr.

Xiaohe Miao for assistance with high-resolution X-ray diffraction and Bo Tang for many fruitful discussions. The research reported in this publication was supported by funding from King Abdullah University of Science and Technology (KAUST).

\section{REFERENCES}

(1) Singh, J. Electronic and Optoelectronic Properties of Semiconductor Structures; Cambridge University Press: Cambridge, U.K., 2007.

(2) Saliba, M.; Matsui, T.; Domanski, K.; Seo, J.-Y.; Ummadisingu, A.; Zakeeruddin, S. M.; Correa-Baena, J.-P.; Tress, W. R.; Abate, A.; Hagfeldt, A. et al. Incorporation of Rubidium Cations into Perovskite Solar Cells Improves Photovoltaic Performance. Science 2016, 354, 206-209.

(3) Yang, W. S.; Noh, J. H.; Jeon, N. J.; Kim, Y. C.; Ryu, S.; Seo, J.; Seok, S. I. HighPerformance Photovoltaic Perovskite Layers Fabricated through Intramolecular Exchange. Science 2015, 348, 1234-1237.

(4) Saidaminov, M. I.; Adinolfi, V.; Comin, R.; Abdelhady, A. L.; Peng, W.; Dursun, I.; Yuan, M.; Hoogland, S.; Sargent, E. H.; Bakr, O. M. Planar-Integrated Single-Crystalline Perovskite Photodetectors. Nat. Commun. 2015, 6, 8724.

(5) Lian, Z.; Yan, Q.; Lv, Q.; Wang, Y.; Liu, L.; Zhang, L.; Pan, S.; Li, Q.; Wang, L.; Sun, J.L. High-Performance Planar-Type Photodetector on (100) Facet of $\mathrm{MAPbI}_{3}$ Single Crystal. Sci. Rep. 2015, 5, 16563. 
(6) Zhu, H.; Fu, Y.; Meng, F.; Wu, X.; Gong, Z.; Ding, Q.; Gustafsson, M. V.; Trinh, M. T.; Jin, S.; Zhu, X. Y. Lead Halide Perovskite Nanowire Lasers with Low Lasing Thresholds and High Quality Factors. Nat. Mater. 2015, 14, 636-642.

(7) Cho, H.; Jeong, S.-H.; Park, M.-H.; Kim, Y.-H.; Wolf, C.; Lee, C.-L.; Heo, J. H.; Sadhanala, A.; Myoung, N.; Yoo, S. et al. Overcoming the Electroluminescence Efficiency Limitations of Perovskite Light-Emitting Diodes. Science 2015, 350, 1222-1225.

(8) Tan, Z.-K.; Moghaddam, R. S.; Lai, M. L.; Docampo, P.; Higler, R.; Deschler, F.; Price, M.; Sadhanala, A.; Pazos, L. M.; Credgington, D. et al. Bright Light-Emitting Diodes Based on Organometal Halide Perovskite. Nat. Nanotechnol. 2014, 9, 687-692.

(9) Yakunin, S.; Dirin, D. N.; Shynkarenko, Y.; Morad, V.; Cherniukh, I.; Nazarenko, O.; Kreil, D.; Nauser, T.; Kovalenko, M. V. Detection of Gamma Photons Using SolutionGrown Single Crystals of Hybrid Lead Halide Perovskites. Nat. Photon. 2016, 10, 585-589.

(10) Yakunin, S.; Sytnyk, M.; Kriegner, D.; Shrestha, S.; Richter, M.; Matt, G. J.; Azimi, H.; Brabec, C. J.; Stangl, J.; Kovalenko, M. V. et al. Detection of X-Ray Photons by SolutionProcessed Lead Halide Perovskites. Nat. Photon. 2015, 9, 444-449.

(11) Dursun, I.; Shen, C.; Parida, M. R.; Pan, J.; Sarmah, S. P.; Priante, D.; Alyami, N.; Liu, J.; Saidaminov, M. I.; Alias, M. S. et al. Perovskite Nanocrystals as a Color Converter for Visible Light Communication. ACS Photonics 2016, 3, 1150-1156.

(12) Dong, Q.; Fang, Y.; Shao, Y.; Mulligan, P.; Qiu, J.; Cao, L.; Huang, J. Electron-Hole Diffusion Lengths > $175 \mu \mathrm{m}$ in Solution-Grown $\mathrm{CH}_{3} \mathrm{NH}_{3} \mathrm{PbI}_{3}$ Single Crystals. Science 2015, 347, 967-970.

(13) Shi, D.; Adinolfi, V.; Comin, R.; Yuan, M.; Alarousu, E.; Buin, A.; Chen, Y.; Hoogland, S.; Rothenberger, A.; Katsiev, K. et al. Low Trap-State Density and Long Carrier Diffusion in Organolead Trihalide Perovskite Single Crystals. Science 2015, 347, 519-522.

(14) Saidaminov, M. I.; Abdelhady, A. L.; Murali, B.; Alarousu, E.; Burlakov, V. M.; Peng, W.; Dursun, I.; Wang, L.; He, Y.; Maculan, G. et al. High-Quality Bulk Hybrid Perovskite Single Crystals within Minutes by Inverse Temperature Crystallization. Nat. Commun. 2015, 6, 7586.

(15) Zhumekenov, A. A.; Saidaminov, M. I.; Haque, M. A.; Alarousu, E.; Sarmah, S. P.; Murali, B.; Dursun, I.; Miao, X.-H.; Abdelhady, A. L.; Wu, T. et al. Formamidinium Lead Halide Perovskite Crystals with Unprecedented Long Carrier Dynamics and Diffusion Length. ACS Energy Lett. 2016, 1, 32-37.

(16) Wang, Q.; Chen, B.; Liu, Y.; Deng, Y.; Bai, Y.; Dong, Q.; Huang, J. Scaling Behavior of Moisture-Induced Grain Degradation in Polycrystalline Hybrid Perovskite Thin Films. Energy Environ. Sci. 2017, 10, 516-522.

(17) Leguy, A. M. A.; Hu, Y.; Campoy-Quiles, M.; Alonso, M. I.; Weber, O. J.; Azarhoosh, P.; van Schilfgaarde, M.; Weller, M. T.; Bein, T.; Nelson, J. et al. Reversible Hydration of $\mathrm{CH}_{3} \mathrm{NH}_{3} \mathrm{PbI}_{3}$ in Films, Single Crystals, and Solar Cells. Chem. Mater. 2015, 27, 33973407.

(18) Manser, J. S.; Saidaminov, M. I.; Christians, J. A.; Bakr, O. M.; Kamat, P. V. Making and Breaking of Lead Halide Perovskites. Acc. Chem. Res. 2016, 49, 330-338.

(19) Liu, Y.; Yang, Z.; Cui, D.; Ren, X.; Sun, J.; Liu, X.; Zhang, J.; Wei, Q.; Fan, H.; Yu, F. et al. Two-Inch-Sized Perovskite $\mathrm{CH}_{3} \mathrm{NH}_{3} \mathrm{PbX}_{3}(\mathrm{X}=\mathrm{Cl}, \mathrm{Br}, \mathrm{I})$ Crystals: Growth and Characterization. Adv. Mater. 2015, 27, 5176-5183.

(20) Kadro, J. M.; Nonomura, K.; Gachet, D.; Grätzel, M.; Hagfeldt, A. Facile Route to Freestanding $\mathrm{CH}_{3} \mathrm{NH}_{3} \mathrm{PbI}_{3}$ Crystals Using Inverse Solubility. Sci. Rep. 2015, 5, 11654. 
(21) Zhang, T.; Yang, M.; Benson, E. E.; Li, Z.; van de Lagemaat, J.; Luther, J. M.; Yan, Y.; Zhu, K.; Zhao, Y. A Facile Solvothermal Growth of Single Crystal Mixed Halide Perovskite $\mathrm{CH}_{3} \mathrm{NH}_{3} \mathrm{~Pb}\left(\mathrm{Br}_{1-\mathrm{x}} \mathrm{Cl}_{\mathrm{x}}\right)_{3}$. Chem. Commun. 2015, 51, 7820-7823.

(22) Dang, Y.; Liu, Y.; Sun, Y.; Yuan, D.; Liu, X.; Lu, W.; Liu, G.; Xia, H.; Tao, X. Bulk Crystal Growth of Hybrid Perovskite Material $\mathrm{CH}_{3} \mathrm{NH}_{3} \mathrm{PbI}_{3}$. CrystEngComm 2015, 17, 665-670.

(23) Shamsi, J.; Abdelhady, A. L.; Accornero, S.; Arciniegas, M.; Goldoni, L.; Kandada, A. R. S.; Petrozza, A.; Manna, L. N-Methylformamide as a Source of Methylammonium Ions in the Synthesis of Lead Halide Perovskite Nanocrystals and Bulk Crystals. ACS Energy Lett. 2016, $1,1042-1048$.

(24) Chen, Y.-X.; Ge, Q.-Q.; Shi, Y.; Liu, J.; Xue, D.-J.; Ma, J.-Y.; Ding, J.; Yan, H.-J.; Hu, J.S.; Wan, L.-J. General Space-Confined on-Substrate Fabrication of Thickness-Adjustable Hybrid Perovskite Single-Crystalline Thin Films. J. Am. Chem. Soc. 2016, 138, 1619616199.

(25) Nguyen, V.-C.; Katsuki, H.; Sasaki, F.; Yanagi, H. Optically Pumped Lasing in Single Crystals of Organometal Halide Perovskites Prepared by Cast-Capping Method. Appl. Phys. Lett. 2016, 108, 261105.

(26) Nguyen, V.-C.; Katsuki, H.; Sasaki, F.; Yanagi, H. Single-Crystal Perovskites Prepared by Simple Solution Process: Cast-Capping Method. J. Cryst. Growth 2017, 468, 796-799.

(27) Peng, W.; Wang, L.; Murali, B.; Ho, K.-T.; Bera, A.; Cho, N.; Kang, C.-F.; Burlakov, V. M.; Pan, J.; Sinatra, L. et al. Solution-Grown Monocrystalline Hybrid Perovskite Films for Hole-Transporter-Free Solar Cells. Adv. Mater. 2016, 28, 3383-3390.

(28) Cho, N.; Li, F.; Turedi, B.; Sinatra, L.; Sarmah, S. P.; Parida, M. R.; Saidaminov, M. I.; Murali, B.; Burlakov, V. M.; Goriely, A. et al. Pure Crystal Orientation and Anisotropic Charge Transport in Large-Area Hybrid Perovskite Films. Nat. Commun. 2016, 7, 13407.

(29) Saidaminov, M. I.; Abdelhady, A. L.; Maculan, G.; Bakr, O. M. Retrograde Solubility of Formamidinium and Methylammonium Lead Halide Perovskites Enabling Rapid Single Crystal Growth. Chem. Commun. 2015, 51, 17658-17661.

(30) Nayak, P. K.; Moore, D. T.; Wenger, B.; Nayak, S.; Haghighirad, A. A.; Fineberg, A.; Noel, N. K.; Reid, O. G.; Rumbles, G.; Kukura, P. et al. Mechanism for Rapid Growth of Organic-Inorganic Halide Perovskite Crystals. Nat. Commun. 2016, 7, 13303.

(31) Dirin, D. N.; Cherniukh, I.; Yakunin, S.; Shynkarenko, Y.; Kovalenko, M. V. SolutionGrown $\mathrm{CsPbBr}_{3}$ Perovskite Single Crystals for Photon Detection. Chem. Mater. 2016, 28, 8470-8474.

(32) Saidaminov, M. I.; Haque, M. A.; Almutlaq, J.; Sarmah, S.; Miao, X.-H.; Begum, R.; Zhumekenov, A. A.; Dursun, I.; Cho, N.; Murali, B. et al. Inorganic Lead Halide Perovskite Single Crystals: Phase-Selective Low-Temperature Growth, Carrier Transport Properties, and Self-Powered Photodetection. Adv. Opt. Mater. 2017, 5, 1600704.

(33) Rakita, Y.; Kedem, N.; Gupta, S.; Sadhanala, A.; Kalchenko, V.; Böhm, M. L.; Kulbak, M.; Friend, R. H.; Cahen, D.; Hodes, G. Low-Temperature Solution-Grown $\mathrm{CsPbBr}_{3}$ Single Crystals and Their Characterization. Cryst. Growth Des. 2016, 16, 5717-5725.

(34) Saidaminov, M. I.; Almutlaq, J.; Sarmah, S.; Dursun, I.; Zhumekenov, A. A.; Begum, R.; Pan, J.; Cho, N.; Mohammed, O. F.; Bakr, O. M. Pure Cs4 $\mathrm{PbBr}_{6}$ : Highly Luminescent Zero-Dimensional Perovskite Solids. ACS Energy Lett. 2016, 1, 840-845.

(35) Zeldovich, J. Theory of Nucleation and Condensation. Sov. Phys. JETP (Eng. Transl.) 1942, 12, 525. 
(36) Volmer, M.; Weber, A. Keimbildung in Übersättigten Gebilden. Z. Phys. Chem. 1926, 119, 277-301.

(37) Becker, R.; Döring, W. Kinetische Behandlung Der Keimbildung in Übersättigten Dämpfen. Ann. Phys. 1935, 416, 719-752.

(38) Frenkel, J. A General Theory of Heterophase Fluctuations and Pretransition Phenomena. $J$. Chem. Phys. 1939, 7, 538-547.

(39) Laidler, K. J.; King, M. C. Development of Transition-State Theory. J. Phys. Chem. 1983, 87, 2657-2664.

(40) Tiller, W. A. The Science of Crystallization: Microscopic Interfacial Phenomena; Cambridge University Press: Cambridge, U.K., 1991.

(41) Oliver, J. F.; Huh, C.; Mason, S. G. Resistance to Spreading of Liquids by Sharp Edges. J. Colloid Interface Sci. 1977, 59, 568-581.

(42) Singh, P.; Joseph, D. D. Fluid Dynamics of Floating Particles. J. Fluid Mech. 2005, 530, 31-80.

(43) Chang, F.-M.; Sheng, Y.-J.; Tsao, H.-K. Superhydrophobic Floatability of a Hydrophilic Object Driven by Edge Effect. Appl. Phys. Lett. 2009, 95, 204107.

(44) Koenhen, D. M.; Smolders, C. A. The Determination of Solubility Parameters of Solvents and Polymers by Means of Correlations with Other Physical Quantities. J. Appl. Polym. Sci. 1975, 19, 1163-1179.

(45) Zhang, Y.; Huang, F.; Mi, Q. Preferential Facet Growth of Methylammonium Lead Halide Single Crystals Promoted by Halide Coordination. Chem. Lett. 2016, 45, 1030-1032.

(46) Mancini, A.; Quadrelli, P.; Milanese, C.; Patrini, M.; Guizzetti, G.; Malavasi, L. $\mathrm{CH}_{3} \mathrm{NH}_{3} \mathrm{Sn}_{\mathrm{x}} \mathrm{Pb}_{1-\mathrm{x}} \mathrm{Br}_{3}$ Hybrid Perovskite Solid Solution: Synthesis, Structure, and Optical Properties. Inorg. Chem. 2015, 54, 8893-8895.

(47) Stamplecoskie, K. G.; Manser, J. S.; Kamat, P. V. Dual Nature of the Excited State in Organic-Inorganic Lead Halide Perovskites. Energy Environ. Sci. 2015, 8, 208-215.

(48) Horváth, O.; Mikó, I. Spectra, Equilibrium and Photoredox Chemistry of Tri- and Tetraiodoplumbate(II) Complexes in Acetonitrile. J. Photochem. Photobiol. A: Chem. 1998, 114, 95-101.

(49) Guo, Y.; Shoyama, K.; Sato, W.; Matsuo, Y.; Inoue, K.; Harano, K.; Liu, C.; Tanaka, H.; Nakamura, E. Chemical Pathways Connecting Lead(II) Iodide and Perovskite Via Polymeric Plumbate(II) Fiber. J. Am. Chem. Soc. 2015, 137, 15907-15914.

(50) Tian, Y.; Scheblykin, I. G. Artifacts in Absorption Measurements of Organometal Halide Perovskite Materials: What Are the Real Spectra? J. Phys. Chem. Lett. 2015, 6, 3466-3470.

(51) Sarmah, S. P.; Burlakov, V. M.; Yengel, E.; Murali, B.; Alarousu, E.; El-Zohry, A. M.; Yang, C.; Alias, M. S.; Zhumekenov, A. A.; Saidaminov, M. I. et al. Double Charged Surface Layers in Lead Halide Perovskite Crystals. Nano Lett. 2017, 17, 2021-2027.

(52) Stoumpos, C. C.; Malliakas, C. D.; Kanatzidis, M. G. Semiconducting Tin and Lead Iodide Perovskites with Organic Cations: Phase Transitions, High Mobilities, and near-Infrared Photoluminescent Properties. Inorg. Chem. 2013, 52, 9019-9038.

(53) Shaikh, P. A.; Shi, D.; Retamal, J. R. D.; Sheikh, A. D.; Haque, M. A.; Kang, C.-F.; He, J.H.; Bakr, O. M.; Wu, T. Schottky Junctions on Perovskite Single Crystals: LightModulated Dielectric Constant and Self-Biased Photodetection. J. Mat. Chem. C 2016, 4, 8304-8312. 
(54) Liu, Y.; Zhang, Y.; Yang, Z.; Yang, D.; Ren, X.; Pang, L.; Liu, S. Thinness- and ShapeControlled Growth for Ultrathin Single-Crystalline Perovskite Wafers for Mass Production of Superior Photoelectronic Devices. Adv. Mater. 2016, 28, 9204-9209.

(55) Liu, Y.; Sun, J.; Yang, Z.; Yang, D.; Ren, X.; Xu, H.; Yang, Z.; Liu, S. 20-Mm-Large Single-Crystalline Formamidinium-Perovskite Wafer for Mass Production of Integrated Photodetectors. Adv. Opt. Mater. 2016, 4, 1829-1837.

(56) Yucheng, L.; Xiaodong, R.; Jing, Z.; Zhou, Y.; Dong, Y.; Fengyang, Y.; Jiankun, S.; Changming, Z.; Zhun, Y.; Bo, W. et al. 120 Millimeter Single-Crystalline Perovskite and Wafers: To-Wards Viable Applications. Sci China Chem 2017, DOI: 10.1007/s11426-0179081-3.

(57) Fang, Y.; Dong, Q.; Shao, Y.; Yuan, Y.; Huang, J. Highly Narrowband Perovskite SingleCrystal Photodetectors Enabled by Surface-Charge Recombination. Nat. Photon. 2015, 9, 679-686.

(58) Maculan, G.; Sheikh, A. D.; Abdelhady, A. L.; Saidaminov, M. I.; Haque, M. A.; Murali, B.; Alarousu, E.; Mohammed, O. F.; Wu, T.; Bakr, O. M. $\mathrm{CH}_{3} \mathrm{NH}_{3} \mathrm{PbCl}_{3}$ Single Crystals: Inverse Temperature Crystallization and Visible-Blind UV-Photodetector. J. Phys. Chem. Lett. 2015, 6, 3781-3786.

(59) Owens, D. K.; Wendt, R. C. Estimation of the Surface Free Energy of Polymers. J. Appl. Polym. Sci. 1969, 13, 1741-1747.

(60) Rabel, W. Einige Aspekte Der Benetzungstheorie Und Ihre Anwendung Auf Die Untersuchung Und Veränderung Der Oberflächeneigenschaften Von Polymeren. Farbe Lack 1971, 77, 997-1006.

(61) Kaelble, D. H. Dispersion-Polar Surface Tension Properties of Organic Solids. J. Adhes. 1970, 2, 66-81.

(62) Young, T. An Essay on the Cohesion of Fluids. Philos. Trans. R. Soc. London 1805, 95, 65-87.

(63) Ummadisingu, A.; Steier, L.; Seo, J.-Y.; Matsui, T.; Abate, A.; Tress, W.; Grätzel, M. The Effect of Illumination on the Formation of Metal Halide Perovskite Films. Nature 2017, $545,208-212$. 